PAWEL A. ATROSZKO

WIKTOR K. WRÓBEL

PIOTR BEREZNOWSKI

RAFAŁ LAWENDOWSKI

University of Gdańsk, Poland

Institute of Psychology

\title{
THE RELATIONSHIP \\ BETWEEN STUDY ADDICTION AND EXAMINATION STRESS AMONG STUDENTS OF MUSIC ACADEMIES
}

Previous studies have shown that study addiction is related to worse academic performance among music academy students as well as in the general population of students, suggesting that excessive examination stress may impair their performance on exams. The aim of this study was to investigate the relationship between the newly developed concept of "study addiction" and examination stress among students of music academies. Study addiction has been defined within the framework of theory and research on work addiction as a potential behavioral addiction. A cross-sectional correlational study was conducted, with a sample of 132 students of music academies in Poland. The Bergen Study Addiction Scale, assessing seven core addiction symptoms related to studying, was administered together with a commonly used measure of personality and single-item measures of examination stress and learning engagement. Multiple hierarchical regression analysis showed that study addiction was related to higher examination stress above and beyond personality traits. What is more, while study addiction showed a positive relationship with examination stress, learning engagement showed a negative association with examination stress. The results suggest that, among music academies students, study addiction is related to higher stress during exams and that study addiction and learning engagement are different constructs. Taking into account the relationship of study addiction with higher stress in situations of being evaluated, future studies are warranted that would link study addiction to music performance anxiety, which is one of the most widely studied phenomena in the psychology of music.

Keywords: musicians; examination stress; learning engagement; personality; study addiction; workaholism; work addiction.

Corresponding author: PAWEŁ ANDRZEJ ATROSZKo-University of Gdańsk, Institute of Psychology, ul. Bażyńskiego 4, 80-309 Gdańsk, Poland; e-mail: p.atroszko@ug.edu.pl

We would like to thank Professor Barbara Halec and Professor Michał Kierzkowski for their assistance with data collection. 


\section{INTRODUCTION}

Recently, study addiction has been identified as a potential early form of work addiction (Atroszko, 2018, 2019a; Griffiths, Demetrovics, \& Atroszko, 2018), which has been recognized as a serious problem for decades (Atroszko, 2019b; Atroszko \& Griffiths, 2017). It was conceptualized within contemporary theories of work addiction and it can be defined accordingly as "characterized by a compulsion to study and preoccupation with study activities leading to a significant harm and distress of a functionally impairing nature to the individual and/or other significantly relevant relationships (friends, family). The behavior is characterized by the loss of control over the studying activity and persists over a significant period of time. This problematic study-related behavior can have varying intensity from mild to severe" (Atroszko, Demetrovics, \& Griffiths, 2019, p. 9; see Atroszko, Andreassen, Griffiths, \& Pallesen, 2015, p. 75). Study addiction was found to be related to work addiction in longitudinal research (Atroszko, Andreassen, Griffiths, \& Pallesen, 2016a) and showed similar temporal stability to work addiction (Atroszko, Andreassen, Griffiths, \& Pallesen, 2016b). Both addictions show seven core addiction symptoms: salience, mood modification, tolerance, withdrawal, conflict, relapse, and problems (Atroszko et al., 2015). Moreover, both of them are related to higher engagement in studying/working, longer time devoted to studying/working, key personality traits (higher neuroticism and conscientiousness), lower performance levels, impaired general health, decreased quality of life, poor sleep, and higher perceived stress (Atroszko et al., 2015; Griffiths et al., 2018). Furthermore, study addiction and work addiction show similar prevalence rates, which are typically around $8-10 \%$ (Atroszko, 2015; Griffiths et al., 2018).

While there are different frameworks distinguishing healthy and unhealthy engagement in particular behaviors (e.g., Vallerand, 2015), it should be emphasized that study addiction fits well into the diagnostic criteria for behavioral addiction. It phenomenologically manifests itself as a compulsive behavior, shows a relationship with deteriorated functioning, and is temporally stable, stability being one of the key criteria for the validity of a psychiatric disorder (see Atroszko, 2019a, 2019b; Atroszko \& Griffiths, 2017; Atroszko et al., 2019; Griffiths et al., 2018). In the context of the present study, higher examination stress (also known as test anxiety) can be considered to be yet another facet of dysfunctional behavior. It is strictly related to performance anxiety and music performance anxiety (MPA; for an overview, see Kantor-Martynuska \& Domaradzka, 2018). While examination stress is a general construct related to any 
situation of being formally evaluated (especially within the education system), MPA is specifically related to music performance situations. Since constant evaluation within the education system, especially in music academies, is one of the central elements of students' life, it can be argued that higher examination stress will have a profound negative effect on young adults' general psychosocial functioning. For these reasons, analyzing study addiction within a clinical framework makes it possible to put particular findings in a larger picture of disordered behavior and to understand both its antecedents and its consequences, such as those stemming from chronic stress related to being frequently evaluated.

The differences between study addiction and learning engagement, two constructs that are related but significantly differ in terms of antecedents and consequences, are continuously investigated, and the results of the previous studies parallel the findings related to work engagement and work addiction (Atroszko, 2018, 2019a; Atroszko et al., 2015, 2019; Griffiths et al., 2018). Learning engagement can be defined as general willingness to invest time and effort in learning both in and out of school/university (Lukowicz et al., 2017a), and thus it comprises typically identified behavioral engagement (involvement in academic and social or extracurricular activities), emotional engagement (positive and negative reactions to lecturers, other students, academics, and the university), cognitive engagement (thoughtfulness and willingness to make the effort necessary to comprehend complex ideas and master difficult skills) (Fredricks, Blumenfeld, \& Paris, 2004). Both learning engagement and study addiction have been found to be related to a greater amount of time devoted to learning; however, engaged individuals typically do not experience adverse consequences but rather the opposite - that is, decreased levels of perceived stress as well as increased quality of life and school performance (Atroszko et al., 2015).

Previous studies have shown that study addiction is related to worse academic performance (lower grade point average; GPA) in music academy students (Lawendowski, Bereznowski, Wróbel, Kierzkowski, \& Atroszko, 2019) as well as in the general population of students (Atroszko, 2015; Atroszko et al., 2015). One of the crucial factors influencing academic performance is examination stress (Chapell et al., 2005; von der Embse, Jester, Roy, \& Post, 2018). Examination stress has been linked to lower emotional stability, conscientiousness, and openness to experience, to lower GPA, and to being female across all education levels (von der Embse et al., 2018). Excessive stress experienced during situations of being formally evaluated may hinder musicians' performance during exams (Cassady \& Johnson, 2002; Rae \& McCambridge, 2004). In a recent study among musicians, social anxiety was negatively related to academic performance 
(GPA), but only for those individuals who also showed high study addiction (Lawendowski et al., 2019). Although social anxiety and examination stress are not synonymous, they are closely related, as both of them include the component of fear of being negatively evaluated (they differ in terms of what consequences are feared, as negative test results are primarily non-social, e.g., slowing academic progression or repeating the failed course; Bögels et al., 2010). In the light of these results, it seems plausible that study addiction, which has been conceptualized as an ineffective coping strategy, can be a way of compensating for negative emotions caused by social anxiety and, possibly, by examination stress through over-studying (Atroszko, 2015; Atroszko, 2018). This means that study addicts may use increased practice or learning as a means of dealing with their feelings of anxiety and doubt and with other negative experiences or psychological problems. Engaging in behavior requiring high focus can be a strategy employed to get away from negative emotions and to induce positive ones (at least at the beginning). Recently, this mechanism was debated in the context of exclusion criteria for work addiction and other behavioral addictions (Kardefelt-Winther et al., 2017). It was suggested that, consistently with the way all addictions are conceptualized and with the coping/emotion regulation function of addiction, the identification of underlying psychological problems and negative emotions should not be considered an exclusion criterion when diagnosing a behavioral addiction (Atroszko, 2019a, 2019b; Atroszko et al., 2019).

In previous studies, women showed higher levels of exam stress (Cassady \& Johnson, 2002; Everson, Millsap, \& Rodriguez, 1991) and study addiction (Atroszko, 2015; Atroszko et al., 2015). Addiction research shows that women are more susceptible to developing addictions related to socially sanctioned behaviors and that they progress more quickly than men into addiction (Fattore, Melis, Fadda, \& Fratta, 2014). Examination stress has been found to be related to personality, mainly to neuroticism (Chamorro-Premuzic, Ahmetoglu, \& Furnham, 2008), which is also related to study addiction (Atroszko, 2015; Atroszko et al., 2015) and gender (Lynn \& Martin, 1997). This suggests that gender, as well as personality, should be controlled for when investigating the relationship between study addiction and exam stress to see whether the relationship is above and beyond the effects of these variables.

The relationship between study addiction, learning engagement, and examination stress seems to be a complex one. It can be expected that any type of higher involvement in studying may result in higher exam stress because the time and effort devoted to study are evaluated and there is a potential risk of loss (i.e., worse grade, loss of respect etc.; Lazarus \& Folkman, 1987). Previous studies showed that examination stress was positively related to learning 
engagement in the general population of students (Atroszko, 2015; Łukowicz et al., 2017b) even when study addiction was controlled for (Atroszko, 2015). Controlling for learning engagement when investigating the relationship between study addiction and exam stress can provide better estimates of the effect of unhealthy involvement above and beyond what can be expected from general higher engagement in learning behavior.

Based on the theory and previous research on study addiction, learning engagement, and examination stress, we hypothesized that in students of musical academies higher examination stress would be related to higher study addiction, above and beyond demographics, personality, and learning engagement.

\section{METHOD}

\section{Ethical issues}

The research was carried out in accordance with the Helsinki Declaration. All collected data was anonymous, and participants were informed of all relevant details regarding the study. Obtaining written informed consent was not considered necessary, as the voluntary completion of questionnaires was assumed to be an expression of such consent and no medical information was collected. The authors were from different universities than the participants and had no contact with the participants before, during, and after data collection.

\section{Procedure}

Data collection took place from April till May 2017, that is from about one and a half months after the end of winter end-of-term examinations until about two weeks before the beginning of summer end-of-term examinations. The study used convenience sampling. It was a pen-and-pencil cross-sectional study. Students were invited by deans of each university to participate in the study anonymously during lectures or classes; the deans estimated that more than $95 \%$ of the students agreed to do so. Participation in the study was entirely anonymous, and no monetary or other rewards were offered.

\section{Sample}

The sample comprised 132 undergraduate students: 82 females (62.1\%), 48 males (36.4\%), and two persons $(1.5 \%)$ who did not report their gender, with a mean age of $M=22.36$ years $(S D=2.98)$. The participants were studying at the 
Stanisław Moniuszko Academy of Music in Gdańsk and the Academy of Art in Szczecin. The students were from different faculties, courses, and years of musical studies (mean semester $=4.4, S D=2.6$ ). As regards their distribution across faculties: 52 participants (39.4\%) studied Arts Education in Music, $35(25.8 \%)$ studied Instrumental Studies, 18 (13.6\%) studied Jazz and Popular Music, $11(8.3 \%)$ studied Vocal Performance, 4 (3.0\%) studied Composition and Music Theory, $2(1.5 \%)$ studied Conducting, 1 person $(0.8 \%)$ was a student of both Arts Education in Music and Instrumental Studies, 1 person (0.8\%) studied both Jazz and Popular Music and Composition and Music Theory, and 8 students $(6.1 \%)$ did not report their faculty. Missing data were imputed when they were missing at random, and only a very small portion of data were missing (less than $2 \%$ overall). To perform the imputation, we used the Expectationmaximization (EM) algorithm within SPSS 24.0, which provides unbiased estimates of parameters.

\section{Measures}

Study addiction. Study addiction was measured with the Bergen Study Addiction Scale (BStAS; Atroszko et al., 2015), which includes seven items that are based on the core elements of addiction (Griffiths, 2005). The questions pertain to experiences during the past 12 months. For example, conflict is measured with the following question: "How often during the last year have you deprioritized hobbies, leisure activities, and exercise because of your studying?" Each item is rated on a 5-point Likert scale with responses from never (1) to always (5). BStAS showed good validity and reliability in previous research (Atroszko, 2015; Atroszko et al., 2015, 2016a, 2016b). In the present sample, the Cronbach's alpha reliability coefficient was .84 .

Learning engagement. Learning engagement was assessed with a single-item measure, which asked the following question: "How engaged in learning are you?" (Atroszko, 2014). The answer was provided on a 7-point Likert scale from I am not at all engaged (1) to I am completely engaged (7). The measure showed good validity and test-retest reliability (intraclass correlation coefficient [ICC] was .77) in previous research (Atroszko, 2014; Atroszko et al., 2015; Łukowicz et al., 2017a). For more information on how this instrument was constructed and validated, see Łukowicz et al. (2017a).

Personality. Ten Item Personality Inventory (TIPI; Gosling, Rentfrow, \& Swann, 2003) adapted into Polish by Atroszko (2015) was used to assess the Big Five personality traits: extraversion, agreeableness, conscientiousness, emotional 
stability, and openness to experience. Each scale in this inventory consists of two items rated on a 7-point Likert scale from disagree strongly (1) to agree strongly (7). The measure showed good validity and reliability in previous research on students (Atroszko, 2015; Atroszko et al., 2015, 2016a, 2016b). In the present sample, the Spearman-Brown reliability coefficient was .64 for Extraversion, .28 for Agreeableness, .61 for Conscientiousness, .58 for Emotional Stability, and .33 for Openness to Experience. As the authors of the scale argue, TIPI demonstrates good validity and biased estimates of reliability using internal consistency measures should be expected due to a very small number of items. Therefore, less biased measures of reliability should be used, such as test-retest reliability, which yielded acceptable correlations between two measurements with a 6 -week interval between them for the original scale, varying from .62 for Openness to .77 for Extraversion (Gosling et al., 2003).

Examination stress. Examination stress was measured with a single-item measure, which asked the following question: "How stressed are you usually during the exams you take as part of your studies?" (Atroszko, 2014). The answer was provided on a 7-point Likert scale from I am not at all stressed (1) to I am completely stressed (7). The measure showed good validity (Atroszko, 2015) and test-retest reliability (intraclass correlation coefficient [ICC] was .78) in previous research (Atroszko, 2014; Łukowicz et al., 2017b). For more information on how this scale was constructed and validated, see Łukowicz et al. (2017b).

\section{Statistical analysis}

All analyses were conducted using IBM SPSS 24.0. Means, standard deviations, percentages, and reliability coefficients were calculated. To examine the associations between the study variables, we computed point-biserial correlation coefficients and Pearson product-moment correlation coefficients, depending on the measurement scale applied. We performed a hierarchical multiple regression analysis, in which examination stress was a dependent variable. Demographic variables were entered first, followed by the Big Five personality traits, then learning engagement, and finally study addiction. Such order is in accordance with the standard approach of entering demographic and controlled variables first. Learning engagement and study addiction were entered separately, as this allowed us to investigate the amount of variance explained by learning engagement and study addiction above and beyond the previously examined variables. For linear regression analysis, we conducted preliminary analyses to 
ensure no violation of the assumptions of normality, linearity, multicollinearity, and homoscedasticity. The assumptions of regression analysis were not violated. The distribution of exam stress was normal, the relationships between the predictors and the outcome variable were linear, the highest VIF was 1.66, and the residuals were randomly distributed around 0 . All tests were two-tailed, and the significance level was set at $\alpha=.05$.

\section{RESULTS}

\section{Descriptive statistics}

Table 1 presents the mean scores, standard deviations, and percentages for the study variables. Study addiction was positively correlated with exam stress and learning engagement. On the other hand, learning engagement did not show significant correlation with exam stress.

Table 1. Mean Scores, Standard Deviations, Percentages, and Correlation Coefficients (PointBiserial, Pearson Product-Moment) Between Study Variables

\begin{tabular}{|c|c|c|c|c|c|c|c|c|c|c|c|c|}
\hline Variables & 1. & 2. & 3. & 4. & 5. & 6. & 7. & 8. & 9. & 10. & Means $/ \%$ & $S D$ \\
\hline 1. Study addiction & - & & & & & & & & & & 17.24 & 5.75 \\
\hline 2. Gender ${ }^{\mathrm{a}}$ & -.10 & - & & & & & & & & \multicolumn{3}{|c|}{$63.1 \%$ female } \\
\hline 3. Age & .06 & .11 & - & & & & & & & & 22.36 & 2.98 \\
\hline 4. Extraversion & $-.20 *$ & -.08 & .02 & - & & & & & & & 8.90 & 2.76 \\
\hline 5. Agreeableness & .02 & -.04 & -.10 & .00 & - & & & & & & 10.73 & 2.03 \\
\hline 6. Conscientiousness & .08 & -.06 & .02 & -.11 & .12 & - & & & & & 10.07 & 2.47 \\
\hline 7. Emotional stability & -.02 & .02 & .21 & * . .11 & $.26^{* *}$ & $.24 * *$ & - & & & & 8.25 & 2.50 \\
\hline $\begin{array}{l}\text { 8. Openness to } \\
\text { experience }\end{array}$ & .03 & .02 & .07 & $.28^{* *}$ & .02 & .12 & -.08 & - & & & 11.14 & 2.10 \\
\hline $\begin{array}{l}\text { 9. Learning } \\
\text { engagement }\end{array}$ & $.48^{* * *}$ & -.07 & .00 & -.13 & .07 & $.37 * * *$ & $.17^{\dagger}$ & $.20 *$ & - & & 5.03 & 1.22 \\
\hline 10. Exam stress & $.19^{*}$ & $-.25^{* *}$ & -.11 & $-.16^{\dagger}$ & -.06 & -.01 & -.14 & -.07 & -.05 & - & 5.04 & 1.51 \\
\hline $\begin{array}{l}\text { 11. Study addiction } \\
\text { cut-off }\end{array}$ & $.69^{* * *}$ & -.07 & .11 & -.03 & .02 & .05 & .12 & .08 & $.27 * * .1$ & 13 & $15.9 \%$ add & dicted \\
\hline
\end{tabular}

\section{Regression analysis}

The regression analysis for examination stress (see Table 2) showed that the independent variables (gender, age, extraversion, agreeableness, conscientiousness, emotional stability, openness to experience, learning engagement, and 
study addiction) explained a total of $16.4 \%$ of the variance, $F(9,111)=2.42$, $p=.015$. The significant independent variables in Step 4 were gender $(\beta=-.26$, $p=.005)$, learning engagement $(\beta=-.22, p=.047)$, and study addiction $(\beta=.26, p=.012)$.

Table 2. Results of Hierarchical Multiple Regression Analyses in Which Study Addiction, Learning Engagement, Gender, Age, and the Big Five Personality Traits Were Regressed on Exam Stress $(\mathrm{N}=121$ due to listwise deletion of observations with missing data)

\begin{tabular}{|c|c|c|c|c|c|c|}
\hline Predictor & $B$ & $S E$ & $\beta$ & $t$ & $p$ & $\Delta R^{2}$ \\
\hline Step 1 & 6.17 & 1.03 & & 5.98 & .000 & $.070^{*}$ \\
\hline Gender $^{\mathrm{a}}$ & -0.78 & 0.28 & -.24 & -2.72 & .007 & \\
\hline Age & -0.04 & 0.05 & -.08 & -0.85 & .397 & \\
\hline Step 2 & 7.88 & 1.55 & & 5.08 & .000 & .040 \\
\hline Gender $^{\mathrm{a}}$ & -0.84 & 0.29 & -.26 & -2.92 & .004 & \\
\hline Age & -0.03 & 0.05 & -.06 & -0.63 & .530 & \\
\hline Extraversion & -0.09 & 0.05 & -.15 & -1.61 & .111 & \\
\hline Agreeableness & -0.06 & 0.07 & -.07 & -0.80 & .428 & \\
\hline Conscientiousness & -0.00 & 0.06 & -.00 & -0.04 & .969 & \\
\hline Emotional stability & -0.05 & 0.06 & -.07 & -0.75 & .457 & \\
\hline Openness to experience & -0.01 & 0.07 & -.01 & -0.15 & .879 & \\
\hline Step 3 & 8.18 & 1.60 & & 5.13 & .000 & .005 \\
\hline Gender $^{\mathrm{a}}$ & -0.86 & 0.29 & -.27 & -2.97 & .004 & \\
\hline Age & -0.03 & 0.05 & -.06 & -0.67 & .506 & \\
\hline Extraversion & -0.10 & 0.05 & -.17 & -1.74 & .085 & \\
\hline Agreeableness & -0.06 & 0.07 & -.08 & -0.82 & .415 & \\
\hline Conscientiousness & 0.01 & 0.06 & -.02 & 0.19 & .852 & \\
\hline Emotional stability & -0.04 & 0.06 & -.06 & -0.61 & .543 & \\
\hline Openness to experience & 0.00 & 0.07 & .00 & 0.05 & .963 & \\
\hline Learning engagement & -0.10 & 0.12 & -.08 & -0.82 & .412 & \\
\hline Step 4 & 7.58 & 1.58 & & 4.81 & .000 & $.049^{*}$ \\
\hline Gender $^{\mathrm{a}}$ & -0.81 & 0.28 & -.26 & -2.90 & .005 & \\
\hline Age & -0.05 & 0.05 & -.09 & -0.97 & .333 & \\
\hline Extraversion & -0.07 & 0.05 & -.13 & -1.38 & .169 & \\
\hline Agreeableness & -0.07 & 0.07 & -.09 & -0.95 & .344 & \\
\hline Conscientiousness & 0.04 & 0.06 & .06 & 0.59 & .554 & \\
\hline Emotional stability & -0.02 & 0.06 & -.03 & -0.34 & .736 & \\
\hline Openness to experience & 0.01 & 0.07 & .01 & 0.15 & .879 & \\
\hline Learning engagement & -0.28 & 0.14 & -.22 & -2.00 & .047 & \\
\hline Study addiction & 0.07 & 0.03 & .26 & 2.56 & .012 & \\
\hline Total $R^{2}$ & & & & & & $.164 *$ \\
\hline$n$ & & & & & & 121 \\
\hline
\end{tabular}

Note. ${ }^{\mathrm{a}} 0=$ female; $1=$ male; $* p<.05$. 
To ensure that agreeableness and openness to experience (two subscales with low reliability) did not bias other regression coefficients in the model, we ran the second analysis without these two (see Table A1 in Appendix). The results were almost identical.

\section{DISCUSSION}

Study addiction was related positively to examination stress above and beyond personality traits (hypothesis substantiated). This is congruent with previous studies showing that study addiction is related to higher examination stress, general perceived stress, anxiety, and worse academic performance in the general population of students (Atroszko, 2015; Atroszko et al., 2015) as well as with a study which showed that study addiction is related to worse academic performance, higher perceived stress, and social anxiety in students of music academies (Lawendowski et al., 2019). Excessive stress experienced during situations of being formally evaluated may impair musicians' performance during exams (Rae \& McCambridge, 2004; see also Cassady \& Johnson, 2002; Chapell et al., 2005). This was shown by the results of studies focused on how music performance anxiety disorganizes artistic work, reduces the pleasure of performance, and deteriorates musicians' performance, which can lead to ruining a promising career (Steptoe, 1989; Topoğlu, 2014; Wesner, Noyes, \& Davis, 1990; Yoshie, Kudo, Murakoshi, \& Ohtsuki, 2009). In the light of these and previous results, it seems that study addiction can be a way of compensating for examination stress, social anxiety, and possibly music performance anxiety (Lawendowski et al., 2019). However, longitudinal studies are needed to confirm this causal mechanism.

Furthermore, in the present study learning engagement was negatively related to examination stress. This result is not in line with the assumption that any type of higher involvement in studying may result in higher exam stress due to the time and effort investment and the potential risk of loss. However, it provides further evidence that study addiction and learning engagement are different constructs (Atroszko 2015, 2018; Atroszko et al., 2015; Atroszko \& Griffiths, 2017; Griffiths et al., 2018). What is more, this result suggests that in many cases higher exam stress in highly engaged students may be completely attributable to the unhealthy aspects of their involvement- that is, to the components of study addiction. 
Additionally, women showed higher levels of exam stress than men, which is consistent with previous studies (Cassady \& Johnson, 2002; Everson, Millsap, \& Rodriguez, 1991). Women have also been found to show higher levels of study addiction (Atroszko, 2015; Atroszko et al., 2015; Lawendowski et al., 2019). More attention should be devoted to the vulnerabilities related to gender differences in these variables, as it seems that women are more at risk of both becoming addicted to studying and suffering the negative consequences of this addiction. This is congruent with addiction literature showing that women are more susceptible to developing addictions related to socially sanctioned forms of indulgence (Fattore et al., 2014). In the case of exam stress, the factors increasing it in the first place (such as higher social anxiety) may contribute to developing study addiction as a compensatory behavior, and progressing study addiction may in turn, with time, increase exam stress. Such a specific dysfunctional feedback loop has been suggested as one of the main mechanisms behind developing study addiction, and the initial data from several studies have supported its validity (Atroszko, 2015). More longitudinal studies are required to further substantiate this model.

\section{Strengths and limitations}

As far as the limitations of the present study are concerned, the sample was relatively small, which significantly reduces the power of the analyses. The sample was gathered using convenience sampling; therefore, the results of the present study cannot be generalized to other populations without some reservation. Moreover, internal consistencies were very low in the case of two personality trait subscales (i.e., agreeableness and openness to experience), which may have biased the estimates of regression coefficients. However, the exclusion of these variables from the regression analysis did not change the interpretation of the results (see Table A1 in Appendix). Furthermore, the limitations of self-report data (such as social desirability bias, recall bias, etc.) and the cross-sectional character of the study need to be taken into account while interpreting the results. Examination stress and learning engagement were investigated using single-item measures. This means the limitations of such tools have to be taken into account (e.g., the limited variance of the results which might have caused an underestimation of the strength of the correlations and regression estimates).

As regards the strengths of the present study, to our knowledge, it is the first study to investigate the relationship between study addiction and examination stress in music academies students. Valid and reliable measures of personality, 
examination stress and learning engagement were used. Consequently, this study significantly adds to the existing literature on study and work addiction and behavioral addictions and provides more insights regarding the possible consequences and regulatory mechanisms of study addiction in musicians (such as potential increased effort in response to high examination stress). Since it is a cross-sectional study, these regulatory mechanisms need to be further investigated in longitudinal studies, which can yield more evidence of potential causal relationships.

\section{Conclusions and future research directions}

Based on the findings of the present investigation, it can be concluded that study addiction is positively related to examination stress in young musicians, while learning engagement is negatively related to examination stress. The results provide further evidence that study addiction and learning engagement are different constructs with potentially different consequences for students' functioning. Future studies should include multi-item and perhaps multidimensional, widely used measures of examination stress and learning engagement to increase their reliability and variance; they should further inspect the effects of study addiction on the cognitive, emotional, social, and behavioral dimensions of examination stress (see Łukowicz et al., 2017a, 2017b; von der Embse et al., 2018). More studies on study addiction among musicians are warranted. A mediation analysis investigating examination stress as a potential mediator between study addiction and measures of academic performance would provide more support for the hypothesis that study addiction has a negative influence on students' achievements through the excessive stress they experience in evaluation situations. Such a study should control for all known factors influencing academic performance (e.g., conscientiousness, neuroticism, and learning engagement) and should include fairly large samples to yield sufficient statistical power. In the light of the results of this as well as previous research showing a consistent link between study addiction and different anxiety constructs (examination stress, general anxiety, and social anxiety), it is highly recommended to investigate both theoretical and empirical links between study addiction and music performance anxiety, which is one of the most widely studied phenomena in the psychology of music. Furthermore, the pattern of relationships between gender, personality, exam stress, and study addiction requires more systematic research.

The consistent picture of a study addicted individual emerges from this and previous studies pointing to the urgent need for devoting more attention to the 
type of high involvement in students. Early prevention and intervention programs are needed to decrease the risks of study addiction and, potentially, the risks of future work addiction, as well as to cultivate healthy passion in students.

\section{REFERENCES}

Atroszko, P. A. (2014). Developing brief scales for educational research: Reliability of single-item self-report measures of learning engagement and exam stress. In M. McGreevy \& R. Rita (Eds.), Proceedings of the 1st Biannual CER Comparative European Research Conference (pp. 172-175). London, United Kingdom: Sciemcee Publishing. Retrieved from http://www. sciemcee.org/library/proceedings/cer/cer2014_proceedings01.pdf\#page $=172$

Atroszko, P. A. (2015). The structure of study addiction: Selected risk factors and the relationship with stress, stress coping and psychosocial functioning (Unpublished doctoral thesis). University of Gdańsk, Gdańsk, Poland.

Atroszko, P. A. (2018). Commentary on: The Bergen Study Addiction Scale: Psychometric properties of the Italian version. A pilot study. Theoretical and methodological issues in the research on study addiction with relevance to the debate on conceptualising behavioural addictions. Psychiatria $i$ Psychologia Kliniczna, 18(3), 276-282. doi: 10.15557/PiPK. 2018.0034

Atroszko, P. A. (2019a). Response to: Loscalzo and Giannini (2018). A boon of incoherence: Insights on the relationship between study/work addiction and obsessive-compulsive personality disorder. Psychiatria i Psychologia Kliniczna, 19(2), 237-243. doi:10.15557/ PiPK.2019.0025.

Atroszko, P. A. (2019b). Work addiction as a behavioural addiction: Towards a valid identification of problematic behaviour. Australian \& New Zealand Journal of Psychiatry, 53(4), 284-285. doi:10.1177/0004867419828496

Atroszko, P. A., Andreassen, C. S., Griffiths, M. D., \& Pallesen, S. (2015). Study addiction A new area of psychological study: Conceptualization, assessment, and preliminary empirical findings. Journal of Behavioral Addictions, 4, 75-84. doi:10.1556/2006.4.2015.007

Atroszko, P. A., Andreassen, C. S., Griffiths, M. D., \& Pallesen, S. (2016a). The relationship between study addiction and work addiction: A cross-cultural longitudinal study. Journal of Behavioral Addictions, 5(4), 708-714. doi:10.1556/2006.5.2016.076

Atroszko, P. A., Andreassen, C. S., Griffiths, M. D., \& Pallesen, S. (2016b). Study addiction: A cross-cultural longitudinal study examining temporal stability and predictors of its changes. Journal of Behavioral Addictions, 5(2), 357-362. doi:10.1556/2006.5.2016.024

Atroszko, P. A., Demetrovics, Z., \& Griffiths, M. D. (2019). Beyond the myths about work addiction: Toward a consensus on definition and trajectories for future studies on problematic overworking: A response to the commentaries on: Ten myths about work addiction (Griffiths et al., 2018). Journal of Behavioral Addictions, 8(1), 7-15. doi:10.1556/2006.8.2019.11

Atroszko, P. A., \& Griffiths, M. D. (2017). Work addiction is not new to the psychological literature and has evolved over time. Global Journal of Addiction \& Rehabilitation Medicine, 3(3), 1-2. doi: 10.19080/GJARM.2017.03.555612 
Bögels, S. M., Alden, L., Beidel, D. C., Clark, L. A., Pine, D. S., Stein, M. B., \& Voncken, M. (2010). Social anxiety disorder: Questions and answers for the DSM-V. Depression and Anxiety, 27(2), 168-189. doi: 10.1002/da.20670

Cassady, J. C., \& Johnson, R. E. (2002). Cognitive test anxiety and academic performance. Contemporary Educational Psychology, 27(2), 270-295.

Chamorro-Premuzic, T., Ahmetoglu, G., \& Furnham, A. (2008). Little more than personality: Dispositional determinants of test anxiety (the Big Five, core self-evaluations, and self-assessed intelligence). Learning and Individual Differences, 18(2), 258-263. doi: 10.1016/ j.lindif.2007.09.002

Chapell, M. S., Blanding, Z. B., Silverstein, M. E., Takahashi, M., Newman, B., Gubi, A., \& McCann, N. (2005). Test anxiety and academic performance in undergraduate and graduate students. Journal of Educational Psychology, 97(2), 268-274. doi: 10.1037/00220663.97.2.268

Everson, H. T., Millsap, R. E., \& Rodriguez, C. M. (1991). Isolating gender differences in test anxiety: A confirmatory factor analysis of the Test Anxiety Inventory. Educational and Psychological Measurement, 51(1), 243-251. doi: 10.1177/0013164491511024

Fattore, L., Melis, M., Fadda, P., \& Fratta, W. (2014). Sex differences in addictive disorders. Frontiers in Neuroendocrinology, 35(3), 272-284. doi: 10.1016/j.yfrne.2014.04.003

Fredricks, J. A., Blumenfeld, P. C., \& Paris, A. H. (2004). School engagement: Potential of the concept, state of the evidence. Review of Educational Research, 74(1), 59-109. doi: 10.3102/ 00346543074001059

Gosling, S. D., Rentfrow, P. J., \& Swann, W. B., Jr. (2003). A very brief measure of the Big-Five personality domains. Journal of Research in Personality, 37, 504-528. doi:10.1016/S00926566(03)00046-1

Griffiths, M. D. (2005). A 'components' model of addiction within a biopsychosocial framework. Journal of Substance Use, 10, 191-197. doi:10.1080/14659890500114359

Griffiths, M. D., Demetrovics, Z., \& Atroszko, P. A. (2018). Ten myths about work addiction. Journal of Behavioral Addictions, 7(4), 845-857. doi: 10.1556/2006.7.2018.05

Kantor-Martynuska, J., \& Domaradzka, E. (2018). Performance anxiety: The need for an integrative approach. Polish Psychological Bulletin, 19(3), 272-282. doi: 10.24425/119495

Kardefelt-Winther, D., Heeren, A., Schimmenti, A., van Rooij, A., Maurage, P., Carras, M., . . . Billieux, J. (2017). How can we conceptualize behavioural addiction without pathologizing common behaviours? Addiction, 112(10), 1709-1715. doi: 10.1111/add.13763

Lawendowski, R., Bereznowski, P., Wróbel, W. K., Kierzkowski, M., \& Atroszko, P. A. (2019). Study addiction among musicians: Measurement, and relationship with personality, social anxiety, performance and psychosocial functioning. Muscae Scientiae. Advance online publication. doi: 10.1177/1029864918822138

Lazarus, R. S., \& Folkman, S. (1987). Transactional theory and research on emotions and coping. European Journal of Personality, 1(3), 141-169. doi:10.1002/per.2410010304

Lynn, R., \& Martin, T. (1997). Gender differences in extraversion, neuroticism, and psychoticism in 37 nations. The Journal of Social Psychology, 137(3), 369-373. doi:10.1080/00224 549709595447

Łukowicz, P., Choynowska, A., Świątkowska, A. M., Bereznowski, P., Wróbel, W. K., \& Atroszko, P. A. (2017a). Validity of single-item self-report measure of learning engagement. In J. Nyćkowiak \& J. Leśny (Eds.), Badania i rozwój młodych naukowców w Polsce-Nauki humanistyczne i spoleczne. Część IV [Young scholars' research and development in Poland- 
The humanities and social sciences. Part 4] (pp. 41-49). Poznań, Poland: Młodzi Naukowcy. Retrieved from http://experior.ug.edu.pl/wp-content/uploads/Validity-of-single-item-self-re port-measure-of-learning-engagement.pdf

Łukowicz, P., Choynowska, A., Świątkowska, A. M., Bereznowski, P., Wróbel, W. K., \& Atroszko, P. A. (2017b). Validity of single-item self-report measure of examination stress. In J. Nyćkowiak \& J. Leśny (Eds.), Badania i rozwój młodych naukowców w Polsce-Nauki humanistyczne i spoteczne. Część IV [Young scholars' research and development in PolandThe humanities and social sciences. Part 4] (pp. 32-40). Poznań, Poland: Młodzi Naukowcy. Retrieved from http://experior.ug.edu.pl/wp-content/uploads/Validity-of-single-item-self-re port-measure-of-learning-engagement.pdf

Rae, G., \& McCambridge, K. (2004). Correlates of performance anxiety in practical music exams. Psychology of Music, 32(4), 432-439. doi: 10.1177/0305735604046100

Steptoe, A. (1989). Stress, coping and stage fright in professional musicians. Psychology of Music, 17(1), 3-11. doi:10.1177/0305735689171001

Topoğlu, O. (2014). Musical performance anxiety: Relations between personal features and state anxiety levels of pre-service music teachers. International Online Journal of Educations Sciences, 6(2), 337-348. doi:10.15345/iojes.2014.02.008

Vallerand, R. J. (2015). The psychology of passion: A dualistic model. New York, NY, US: Oxford University Press.

von der Embse, N., Jester, D., Roy, D., \& Post, J. (2018). Test anxiety effects, predictors, and correlates: A 30-year meta-analytic review. Journal of Affective Disorders, 227, 483-493. doi:10.1016/j.jad.2017.11.048

Wesner, R. B., Noyes, R., Jr., \& Davis, T. L. (1990). The occurrence of performance anxiety among musicians. Journal of Affective Disorders, 18(3), 117-185. doi:10.1016/0165-0327(90)90034-6

Yoshie, M., Kudo, K., Murakoshi, T., \& Ohtsuki, T. (2009). Music performance anxiety in skilled pianists: Effects of social-evaluative performance situation on subjective, autonomic, and electromyographic reactions. Experimental Brain Research, 199(2), 117-126. doi:10.1007/s0 0221-009-1979-y 


\section{APPENDIX}

Table A1. Results of Hierarchical Multiple Regression Analyses in Which Study Addiction, Learning Engagement, Gender, Age, and the Big Five Personality Traits (Without Agreeableness and Openness to Experience) Were Regressed on Exam Stress ( $\mathrm{n}=121$ due to listwise deletion of observations with missing data)

\begin{tabular}{|c|c|c|c|c|c|c|}
\hline Predictor & $B$ & $S E$ & $\beta$ & $t$ & $p$ & $\Delta R^{2}$ \\
\hline Step 1 & 6.17 & 1.03 & & 5.98 & .000 & $.070 *$ \\
\hline Gender $^{\mathrm{a}}$ & -0.78 & 0.28 & -.24 & -2.72 & .007 & \\
\hline Age & -0.04 & 0.05 & -.08 & -0.85 & .397 & \\
\hline Step 2 & 7.21 & 1.27 & & 5.67 & .000 & .034 \\
\hline Gender $^{\mathrm{a}}$ & -0.83 & 0.29 & -.26 & -2.92 & .004 & \\
\hline Age & -0.03 & 0.05 & -.05 & -0.54 & .588 & \\
\hline Extraversion & -0.09 & 0.05 & -.15 & -1.71 & .090 & \\
\hline Conscientiousness & -0.01 & 0.06 & -.01 & -0.12 & .905 & \\
\hline Emotional stability & -0.06 & 0.06 & -.09 & -0.99 & .323 & \\
\hline Step 3 & 7.59 & 1.35 & & 5.61 & .000 & .005 \\
\hline Gender $^{\mathrm{a}}$ & -0.85 & 0.29 & -.27 & -2.97 & .004 & \\
\hline Age & -0.03 & 0.05 & -.05 & -0.56 & .580 & \\
\hline Extraversion & -0.09 & 0.05 & -.17 & -1.81 & .073 & \\
\hline Conscientiousness & 0.01 & 0.06 & .01 & 0.14 & .888 & \\
\hline Emotional stability & -0.05 & 0.06 & -.08 & -0.90 & .371 & \\
\hline Learning engagement & -0.10 & 0.12 & -.08 & -0.83 & .407 & \\
\hline Step 4 & 6.96 & 1.35 & & 5.17 & .000 & $.048 *$ \\
\hline Gender $^{\mathrm{a}}$ & -0.81 & 0.28 & -.25 & -2.88 & .005 & \\
\hline Age & -0.04 & 0.05 & -.07 & -0.83 & .408 & \\
\hline Extraversion & -0.07 & 0.05 & -.13 & -1.40 & .164 & \\
\hline Conscientiousness & 0.03 & 0.06 & .05 & 0.55 & .585 & \\
\hline Emotional stability & -0.04 & 0.06 & -.06 & -0.68 & .504 & \\
\hline Learning engagement & -0.27 & 0.14 & -.22 & -2.00 & .048 & \\
\hline Study addiction & 0.07 & 0.03 & .26 & 2.53 & .013 & \\
\hline Total $R^{2}$ & & & & & & $.157 * *$ \\
\hline$n$ & & & & & & 121 \\
\hline
\end{tabular}

Note. ${ }^{\mathrm{a}} 0=$ female; $1=$ male; $* p<.05 ; * * p<.01$. 